Commentary on: Inflexibly Enacted Traditional Masculinity Norms (IE-TMNs) and Their Impact on Adolescent and Young Adult Depression: The Hybrid Case Study of "Tommy"

\title{
Treating Masculinity: A Commentary on The Hybrid Case Study of "Tommy"
}

\section{GINELLE WOLFE ${ }^{a}$ \& RONALD F. LEVANT ${ }^{\text {a,b }}$}

\author{
a The University of Akron \\ ${ }^{\mathrm{b}}$ Correspondence regarding this article should be sent to Ronald F. Levant, Department of Psychology, Buchtel \\ College of Arts and Sciences, University of Akron, 302 Buchtel Mall, Akron, OH 44325-4301 \\ Email: levant@uakron.edu
}

\begin{abstract}
Dr. Christopher Dewey (2020) wrote up the hybrid case study of "Tommy," a college student who presents with symptoms of masculine depression and alcohol use problems. The importance of this case study is heightened by the current national conversation about masculinity. Context is provided for the topic of men and depression. Consideration is given to the ways Dewey addresses and works as a clinician with traditional masculinity norms that Tommy endorses. Emphasis is given to the way men are socialized at a young age to conform to traditional masculinity norms, and how to work therapeutically with such men. Strengths and critiques of the case are discussed, organized into the following themes: masculine depression, normative male alexithymia, traditional masculinity ideology, discrepancy strain, questioning masculinity, positive masculinity, making masculinity less salient, dealing with problematic alcohol use, family history, trauma, relationships with women, social media consumption, performance as a college student, treatment goals and the course of treatment, and intersectionality.

Key words: traditional masculinity ideology, masculine depression, case study, young adult depression, alcohol use disorder; case study; hybrid case study

Dr. Christopher Dewey's (2020) case study of a young man struggling with alcohol use problems and depression is situated in the current larger conversation about masculinity occurring in our society. Shortly after the approval by the American Psychological Association (APA) of the APA Guidelines for Psychological Practice with Boys and Men in August 2018 (APA, 2018), the topic of masculinity became a topic of national conversation. Masculinity was no longer a topic limited to psychology, but it crossed into other academic disciplines and also leaped into the public sphere. Fox News quickly lambasted the Guidelines and reported conservative reactions to them (Mikelionis, 2019) followed by other conservative media outlets doing the same. Mainstream media sites such as the Washington Post and the Atlantic Magazine soon stepped in, suggesting that the APA Guidelines were worth considering, posing the question of whether we want to continue raising boys to be emotionless (e.g., Mull, 2019).
\end{abstract}


The conversation became very widespread, almost omnipresent for weeks. Seeing the publicity generated by the APA Guidelines, Gillette (2019) released their Superbowl ad that was critical of "toxic masculinity" prior to the Superbowl. The ad depicted a series of men standing at charcoal grills, while images of boys bullying and cyber bullying other children and men sexually harassing women flashed by. Reprising their advertising slogan from the 1980s (Gillette, 1989), the ad asked, is this "the best a man can get?" (For the company to choose to run an enormously expensive Superbowl ad early and potentially dilute its value reflected their judgment that masculinity had become highly topical at that moment. This incident reveals the importance that was then being placed on problematizing masculinity. Though interest has ebbed and flowed, masculinity remains a popular topic and it was even suggested that masculinity was on the November 2020 ballot (Adams \& Frauenheim, 2020; St. Clair, 2020).

\section{MASCULINE DEPRESSION}

The importance of Dewey's case study is thus amplified by the recent national conversation about masculinity. In this context, Dewey focused specifically on masculinity and depression. Addis and Hoffman (2017) reviewed newer gender-aware ways of conceptualizing men's depression, presenting three different models. The first model posits that men's depression can be masked by anger and impulsiveness and expressed through somatic symptoms, due to the internalization of traditional masculinity norms. This clinical presentation, as well as associated behaviors such as problematic alcohol use, tend to mask depression, making it more difficult to make an accurate diagnosis of Major Depressive Disorder (MDD) in men.

The second model asserts that rather than masking depression, the externalizing symptoms previously described represent how depression manifests in men. Addis and Hoffman (2017) note that the DSM-5 criteria for diagnosing MDD may lean more toward its presentation in women, serving to pathologize women and under-diagnose men.

The third model proposes that depression and other psychological disorders cannot be understood "independent of the social construction and learning of gender" (p. 184). Thus, gender socialization is always a factor given the gendered nature of Western culture. In practice it can be difficult to distinguish these models, as any case may have elements of two or all of them. Dewey describes Tommy's symptoms, stating that Tommy experiences "frequent anger and irritability, which, while not DSM-5 criteria for major depressive disorder, are often key features in depressed males" (p. 270). Given this symptom presentation, and the difficulty in teasing out the different models, we will simply refer to Tommy's diagnosis as masculine depression.

\section{NORMATIVE MALE ALEXITHYMIA}

One characteristic of masculine depression is to avoid feelings and mask vulnerable emotions with ones that are more socially acceptable for men to express, such as anger. For example, Tommy states, "being angry doesn't feel as bad" (p. 269). One fraught aspect of childhood masculinity socialization is to shame boys for showing sadness or fear and encourage them to instead show anger and aggression. Through this process, boys learn to transform vulnerable emotions into anger. Levant (2001) provided an example of this when discussing his theory of Normative Male Alexithymia. He described an elementary school boy who gets pushed 
down on the playground by another boy and knows he cannot come back up with a face full of tears. Rather, he must take the experience of being attacked, maybe betrayed, and maybe even the sadness of losing a friend, and roll all these painful emotions up into a fist that he comes up swinging. Boys learn that as matter of course. Some adult men demonstrate this mechanism so automatically that if their feelings are hurt, they immediately become enraged, almost like when you strike a match to magnesium. This is also likely the mechanism by which many men externalize negative feelings as opposed to internalizing them.

Another way of describing Tommy's symptoms is alexithymia, a clinical term that literally means without words for emotions. Tommy describes himself as "not a feelings guy" (p. 254) and instead prefers a problem-solving approach. To delve more deeply into Tommy's experiences with emotions, Dewey might have used the Toronto Alexithymia Scale-20 (Kooiman et al., 2002) or the Normative Male Alexithymia Scale (Levant et al., 2006) to assess for alexithymia. Most boys are reared to conform to traditional masculinity norms, one of which is the injunction to restrict the expression of vulnerable and caring emotions, termed "Restrictive Emotionality." Levant (2001) hypothesized that boys who are reared this way grow up to be at least mildly alexithymic. Thus, this case may have benefitted from further exploring alexithymia and perhaps incorporating interventions designed to treat it, such as Alexithymia Reduction Treatment (ART, Levant et al., 2009).

\section{TRADITIONAL MASCULINITY IDEOLOGY}

Traditional masculinity ideology refers to the cultural beliefs regarding the norms for men's roles that sustain patriarchal practices. Dewey explains the ways in which Tommy has internalized masculinity norms and the rigid ways that he feels men should think, feel, and behave, which he applies to himself. Given the current zeitgeist, in which masculinity has been problematized, the case can clearly benefit from delving into Tommy's internalization of traditional masculinity ideology.

To his credit, Dewey does this using the Meanings of Adolescent Masculinity Scale (Oransky \& Fisher, 2009) to assess Tommy's masculinity. However, this scale was developed for seventh- to tenth-grade boys, and Tommy is an adult college student. It may have been more appropriate to use the Male Role Norms Inventory (Levant et al., 2013), Conformity to Masculine Norms Inventory (Levant et al., 2020), Gender Role Conflict Scale (Wester et al., 2012), or another measure of masculinity that is better suited to Tommy's age. We are curious why the decision to use a masculinity scale for adolescents was used for a college student who presumably is an adult and in any case is engaging in problematic adult behavior.

\section{DISCREPANCY STRAIN}

Additionally, Dewey describes the automatic thoughts Tommy experiences, such as "My dad doesn't like spending time with me because he doesn't think I'm cool or tough," "My family sees me as more like my mom than my dad," and "Do people not respect me because I'm not strong enough?" (p. 278). He describes feeling ashamed of himself, and like a failure, if he does not live up to masculine ideals. These negative thoughts can also be described in terms of "discrepancy strain." Discrepancy strain was introduced as part of the Gender Role Strain 
Paradigm (Levant, 2011; Pleck, 1981, 1995), and refers to the strain resulting from selfperceived discrepancies between one's masculine ideal self and one's masculine actual self. Tommy illustrates this type of strain when he discusses feeling ashamed of himself if he does not live up to his ideals, which in this case are traditional masculinity norms. Dewey states, "While Tommy was able to come up with more adaptive thoughts to challenge these initial cognitions, it was clear that he was perseverating on and wrestling with aspects of his identity that he felt were discordant with traditional masculinity" (p. 278).

\section{QUESTIONING MASCULINITY}

Throughout the case presentation, Dewey emphasized that Tommy had not previously questioned masculinity before. This is an important point to highlight. Because men are socialized in a culture of masculinity which is viewed as the norm, men do not tend to question masculinity. However, when men begin to look at masculinity and think about it, it can have a profound effect as it did with Tommy. Tommy begins to question why he has been masking his emotions, using alcohol to cope with his depression, and conform to masculinity norms. Thus, this is an important component of working with men who experience masculine depression.

\section{POSITIVE MASCULINITY}

We wish to critique Dewey's use of the construct "positive masculinity," such as when he discusses building an alliance with Tommy. Dewey states that he works to explore positive aspects of masculinity such as courage and determination (p. 246). Dewey also uses this construct when he works to help Tommy create his own definition of masculinity and explore the parts of masculinity Tommy likes, such as being strong, in control, and successful (p. 281). When building an alliance with a male client, Dewey tries to focus on the positive aspects of Tommy's manhood, which in our view is way too narrow. We instead recommend having a conversation where the therapist validates Tommy's feelings of frustration in having to come in for mandated treatment due to his drinking and that he is struggling in school, but there are other things going on in his life that are good, such as for example, that he did well enough in high school to get into the college he attends. That is, instead of trying to keep everything under the rubric of masculinity, it might be more productive to identify things that are going well overall in Tommy's life, rather than zeroing in on positive aspects of masculinity at an early stage. Often times, clients come into therapy with tunnel vision on problems, and a focus on the parts of his life that are going well would help counteract that.

\section{MAKING MASCULINITY LESS SALIENT}

Further, we would like to put forth an alternative way to conceptualize the goal of Tommy's therapy. Instead of redefining Tommy's masculine identity in a more flexible way, a better approach might be to help him make his masculine identity less salient. This can facilitate Tommy's exploration of a wider range of attributes and emotions and his outlook of himself as a person rather than limiting his own self exploration to one social identity and the restrictions and roles that accompany masculinity. An example of how this might be done in the therapy is provided below. 
A related point is that Dewey explains how being a man helps him to relate and validate Tommy's concerns in the room. Dewey speaks generally of the importance of building rapport and includes this as his first goal of treatment. He also describes how he could model characteristics that were not traditionally masculine, including participating in an emotionally honest relationship between two men. While this is a good idea, another way to use gender similarity is to bond with Tommy by saying such things as: "We as men have learned to not share our feelings. We've learned that one can't veer too far from the path of masculinity. We were kids back then when we learned these lessons, but we're adults now and need to look at whether those strictures make sense, and if those things we learned when we were six to ten years old make sense now that we are adults."

We take the approach that masculinity is masculinity, no matter how one tries to dance around it; and as the APA Guidelines make clear, based on $40+$ years of research, on the whole masculinity is harmful. It is thus important to help Tommy make masculinity less salient by a borrowing from Albert Einstein and conducting a "thought experiment" in which Tommy reflects on who he was when he first learned the requisites of masculinity, and who he is now. His life has changed from childhood to young adulthood, and maybe what he learned early on is not as relevant to him today.

Given this alternate conceptualization, we critique Dewey's approach of discussing a "good" definition of masculinity. Instead, we propose that it is important to talk about how masculinity was forced on boys during childhood rather than being an intentional choice. As adults, it is important to look at how these strictures that have been internalized and see if they still apply. In Tommy's developmental stage of Emerging Adulthood (Arnett, 2015) and moving toward establishing adult social roles where he will be focused on a primary relationship, pursuing a vocation, and perhaps raising children, perhaps paying a mortgage, Tommy should deal with how life presents to him now.

\section{DEALING WITH PROBLEMATIC ALCOHOL USE}

Dewey indicates that Tommy has received three alcohol violations (p. 242). More information is needed to better understand Tommy's experiences. Given general college policies, we were surprised Tommy would not have received suspensions or an expulsion for this behavior. For the case to be more realistic, more background information would be beneficial. The time it took for Tommy to be mandated to seek counseling seems long in light of what we know about college policies. Something appears to be left out of the context that he was mandated after three violations. Additionally, it would be helpful to know what else the residence staff had done, as it is important to know what has been tried in the past when treating someone. Additionally, when discussing his alcohol use, Dewey describes the ways Tommy is self-medicating, which is another sign of masculine depression.

\section{FAMILY HISTORY}

Tommy's family history can help illuminate his presenting concerns and the challenges that he is dealing with. Dewey observes that both Tommy's mother and maternal grandmother experienced depression, that his parents separated, and that his father and grandfather engaged in problematic alcohol use. Dewey draws comparisons between Tommy's father and grandfather 
throughout the case, on one instance stating, "Like his grandfather, Tommy's father embodied many traditional masculinity norms. He was a risk-taking individual who drank heavily, gambled frequently, and rarely showed any emotions beyond anger and irritation" (p. 256-257). Dewey describes Tommy's recognition of his father and grandfather drinking, and how they both often seemed irritated and engaged in other externalizing behaviors. Tommy also remarks how he believes his father's alcohol use was a barrier to his marriage and ability to keep a job. Additionally, he remarks on his need to lay low when his grandfather drank heavily or was in a bad mood.

These are not minor things, especially to have a history of three generations of alcohol use problems, which prognostically bodes poorly for Tommy, and also suggests a possible genetic component. Given the way his father and grandfather are described, one could make the case that both of these family members were suffering from masculine depression. We see trends of externalizing, irritability, and arguing, as opposed to the prototypical symptoms of MDD. Additionally, even when discussing the grandfather that Tommy likes, his maternal grandfather, he describes him as traditionally masculine and reveals that he chided Tommy for showing too much emotion. This ties back into masculinity, and how Tommy was socialized to restrict his emotions, which his father monitored as well.

\section{TRAUMA}

Overall, the diagnoses given to Tommy fit with the symptoms and history described. However, when looking more closely into his symptoms, it seems that there are likely trauma symptoms as well, as there is evidence of a numbing defense mechanism, and alexithymia is associated with trauma. Trauma is not discussed in this case study, but it may have been informative to look for signs of post-traumatic stress symptoms. Given this case and history, it may have been helpful to include a trauma assessment.

\section{RELATIONSHIPS WITH WOMEN}

Tommy's ex-girlfriend Ashley provided him with what his mother provided -- namely a holding environment, allowing him to be vulnerable and talk about his feelings. At some point Tommy talks about his mother, which serves as a critical point of treatment. This provides context for understanding his internalization of masculinity norms and the way it has impacted his relationship with his mother, other women, and serves to contextualize some of Tommy's relationship concerns. Dewey highlights how Tommy backed away from his mother as he sought to conform more strongly to masculinity norms and avoid being called a "mama's boy." Ashley seemed to fill a role that he could no longer maintain with his mother, which underscores the meaningfulness of the losses, both of his close relationship with his mother and his relationship with his ex-girlfriend.

Tommy described feeling comfortable around his mother, but because he internalized the message that closeness with his mother violated masculinity norms, he used self-denial to separate from this closeness. It would have been helpful to explore this conflict in more depth. For example, Dewey may have given psychoeducation about the process of how boys can disconnect from their mothers as they internalize masculine norms and explore the process of 
how Tommy started detaching with his mother. It may be helpful to ask Tommy what he felt the purpose was, and what he gained and lost from withdrawing from this relationship.

Tommy's breakup with Ashley appears complicated. Additionally, there was an extra painful part to this breakup, cheating, which seems to have forced him into greater adherence to traditional masculinity ideology. He became angry, started engaging in meaningless hookups, became increasingly depressed, and continued to drink as a coping mechanism. This created a vicious cycle, as it is well known that alcohol use amplifies depression (Addis, 2008; Boden \& Fergusson, 2011). People who try to self-medicate their depression with alcohol often wind up becoming more depressed. Indeed, Tommy experienced shame after he drank too much and engaged in actions that did not line up with his values, supporting the notion that his drinking compounded his problems.

\section{SOCIAL MEDIA CONSUMPTION}

Social media is an important component to highlight in the current zeitgeist and the college population. Tommy engages in what is known as "doomscrolling," which describes continuing to scroll through bad news or social media, even though it causes distress and negative emotions (Doomscrolling. 2020), as he checks Ashley's social media pages and sees how happy she is. It is important to note that Tommy showed progress when he stopped or limited this activity.

\section{PERFORMANCE AS A COLLEGE STUDENT}

Tommy goes from being a successful high school student to a middle-of-the-road college student. This is normal for many students who attend college. They can be the smartest kid in high school and go to college where they meet hundreds of others who were the smartest in their high schools. Additionally, Tommy is not as good of an athlete compared to his peers as he was in high school when he gets to college, given that high school athletes play at a lower level. Dewey illustrates this when he discusses Tommy's feeling like he had been a big fish in a small pond but had to transition to not feeling that way when he transitioned to college.

\section{TREATMENT GOALS AND THE COURSE OF TREATMENT}

Dewey recognizes that he needs to create a holding environment, and that it is important to not push too fast given Tommy's fragility. In addition, he highlights the importance of working on creating a beneficial therapeutic relationship (Norcross, 2010) and utilizing the common factors described by Wampold (2010).

Moreover, we agree with his use of motivational interviewing, as this is a well-respected technique in treating substance abuse and motivating change. Dewey effectively uses psychoeducation about substance use and depression, explaining how the two are linked. Dewey strategically uses behavioral activation followed by cognitive techniques and later hones in on emotions. Dewey also effectively brings in issues related to traditional masculinity ideology and facilitates productive conversation with Tommy about masculine norms. 
Dewey does especially well with alcohol use disorder treatment. To gain more information, it may have been beneficial to use the Alcohol Use Disorders Identification Test (AUDIT; Saunders et al., 1993) which measures problematic drinking. Dewey highlights how the drinking offered temporary relief and validated Tommy's wanting to mitigate his unpleasant feelings. This is marked by Tommy's discussion when he begins to acknowledge negative aspects of his problematic drinking and work effort (p. 265). Tommy grasps that this whole process was a downward spiral, which again relates back to the relationship between depression and alcohol problems. Tommy describes the way he became dependent on alcohol and acknowledges that it was difficult for him to talk to women if he was not drinking.

Further, Dewey's use of social norms clarification is beneficial. We see this as a strength of his clinical work and interventions. Essentially, college men generally believe that other college men drink a lot. In social norms clarification, one compiles information on how often people engage in drinking and how much they drink, and then reveals that information to the students. Students are often amazed to find that they have been overestimating. This phenomenon is known as "Pluralistic Ignorance," a helpful term to highlight and use as a strategy for getting people to moderate their drinking, especially since young men often report they are drinking to keep up with their "brothers" (Kilmartin et al., 2008)

\section{INTERSECTIONALITY}

The theory of intersectionality describes how different facets of a person, such as their age, sex, gender, ethnic-racial group membership, and sexual orientation intersect to create their identity. It has been most often applied to marginalized groups, but there is a growing emphasis on "Whiteness studies" (Kolchin, 2002), which tend to emphasize the power and privilege associated with being White. There could have been some investigation of how Tommy experienced or did not experience the power and privilege that comes with being a young, White, cisgender, able-bodied, heterosexual man. It is also of interest to consider how this case may have been different if the client had marginalized social identities. How may this case have been different if Tommy were Black, gay, transgender, or differently abled? This is important to consider when assessing the generalizability of this case study.

\section{SUMMARY}

Overall, Dewey importantly presents ways to discuss masculinity when working with men in a clinical setting. Further, he provides a detailed case of a college student who presents with masculine depression and substance use concerns. Dewey provides context that helps to illuminate and humanize Tommy's concerns, making this a relatable case and easy for practitioners to understand. Also, it flows logically and is comprehensive, providing detailed examples including conceptualizations, measures, interventions, and outcomes. Moreover, Dewey uses appropriate interventions to work with Tommy. This study can serve to help clinicians who are working with men who have internalized traditional masculinity norms. Specifically, this case study would be useful for clinicians who practice with college men. This case may have been improved by utilizing different measures to more accurately assess Tommy's alexithymia, masculinity ideology, and substance use symptoms. 


\section{REFERENCES}

Adams E. \& Frauenheim E. (2020, Oct. 26). Manhood on the ballot: Trump's self-absorbed bullying vs. Biden's compassion and humility. USA today. Retrieved from https://www.usatoday.com/story/opinion/2020/10/26/trump-bullying-biden-compassionmanhood-election-2020-column/3717416001/

Addis, M. E. (2008). Gender and depression in men. Clinical Psychology: Science and Practice, 15(3), 153-168. https://doi.org/10.1111/j.1468-2850.2008.00125.x

Addis, M. E., \& Hoffman, E. (2017). Men's depression and help-seeking through the lenses of gender. In R. F. Levant \& Y. J. Wong (Eds.), The psychology of men and masculinities (p. 171-196). Washington, D.C.: American Psychological Association. https://doi.org/10.1037/0000023-007

American Psychological Association, Boys and Men Guidelines Group. (2018). APA guidelines for psychological practice with boys and men. Retrieved from http://www.apa.org/about/policy/psychological-practice-boys-men-guidelines.pdf

Arnett, J. J. (2015). Emerging adulthood: The winding road from the late teens through the twenties (2nd ed.). New York: Oxford University Press. https://doi.org/10.1093/oxfordhb/9780199795574.013.9

Boden, J. M., \& Fergusson, D. M. (2011). Alcohol and depression. Addiction, 106(5), 906-914.

Dewey, C. (2020). Inflexibly enacted traditional masculinity norms (IE-TMNs) and their impact on adolescent and young adult depression: The hybrid case study of "Tommy." Pragmatic Case Studies in Psychotherapy, 16 (3), Article 1, 237-304. Available: http://pcsp.libraries.rutgers.edu/

Doomscrolling. 2020. Merriam-Webster.com. Retrieved from: https://www.merriam-webster.com/words-at-play/doomsurfing-doomscrollingwords-were-watching

Gillette (1989). Gillette The best a Man can get... YouTube. Retrieved from: https://www.youtube.com/watch?v=ThDBf14qPsc\&ab channel=bebop2905

Gillette (2019, January 13). We believe: The best a man can be. YouTube. Retrieved from: https://www.youtube.com/watch? $\mathrm{v}=\mathrm{koPmuEyP3a0 \& ab}$ channel=Gillette

Kilmartin, C., Smith, T., Green, A., Heinzen, H., Kuchler, M., \& Kolar, D. (2008). A real time social norms intervention to reduce male sexism. Sex Roles: A Journal of Research, 59 (34), 264-273. https://doi.org/10.1007/s11199-008-9446-y

Kolchin, P. (2002). Whiteness studies: The new history of race in America. The Journal of American History, 89 (1), 154-173.

Kooiman, C. G., Spinhoven, P., \& Trijsburg, R. W. (2002). The assessment of alexithymia: a critical review of the literature and a psychometric study of the Toronto Alexithymia Scale-20. Journal of psychosomatic research, 53 (6), 1083-1090.

Levant, R. F. (2001). Desperately seeking language: Understanding, assessing, and treating normative male alexithymia. In G. R. Brooks \& G. E. Good (Eds.), The new handbook of psychotherapy and counseling with men: A comprehensive guide to settings, problems, and treatment approaches, Vol. 1 \& 2 (p. 424-443). New York: Jossey-Bass/Wiley.

Levant, R. F. (2011). Research in the psychology of men and masculinity using the gender role strain paradigm as a framework. American Psychologist, 66, 763-776.

Levant, R. F., Good, G. E., Cook, S. W., O'Neil, J. M., Smalley, K. B., Owen, K., \& Richmond, K. (2006). The normative Male Alexithymia Scale: Measurement of a gender-linked 
syndrome. Psychology of Men \& Masculinity, 7(4), 212-224. https://doi.org/10.1037/15249220.7.4.212

Levant, R. F., Hall, R. J., \& Rankin, T. J. (2013). Male Role Norms Inventory-Short Form (MRNI-SF): Development, confirmatory factor analytic investigation of structure, and measurement invariance across gender. Journal of Counseling Psychology, 60 (2), 228238. https://doi.org/10.1037/a0031545

Also see: http://www.drronaldlevant.com/mrni.html

Levant, R. F., Halter, M. J., Hayden, E. W., \& Williams, C. M. (2009). The efficacy of alexithymia reduction treatment: A pilot study. The Journal of Men's Studies, 17 (1), 7584. https://doi.org/10.3149/jms.1701.75

Levant, R. F., McDermott, R., Parent, M. C., Alshabani, N., Mahalik, J. R., \& Hammer, J. H. (2020). Development and evaluation of a new short form of the Conformity to Masculine Norms Inventory (CMNI-30). Journal of Counseling Psychology, 67(5), 622636. https://doi.org/10.1037/cou0000414

Mikelionis, L. (2019, January 9). 'Traditional masculinity' deemed harmful, could lead to sexual harassment, medical group says. Fox News. Retrieved from:

https://www.foxnews.com/health/american-psychological-association-deems-traditionalmasculinity-harmful-could-lead-to-sexual-harassment

Mull, A. (2019, January 10). Psychology has a new approach to building healthier men: A controversial set of guidelines aims to help men grapple with "traditional masculinity." The Atlantic. Retrieved from: https://www.theatlantic.com/health/archive/2019/01/traditionalmasculinity-american-psychological-association/580006/

Norcross, J. C. (2010). The therapeutic relationship. In B. L. Duncan, S. D. Miller, B. E. Wampold, \& M. A. Hubble (Eds.), The heart and soul of change: Delivering what works in therapy (p. 113-141). American Psychological Association. https://doi.org/10.1037/12075-004

Oransky, M. \& Fisher, C. B. (2009). The development and validation of the Meanings of Adolescent Masculinity Scale. Psychology of Men \& Masculinity, 10, 57-72

Pleck, J. H. (1981). The myth of masculinity. Cambridge, MA: MIT Press.

Pleck, J. H. (1995). The gender role strain paradigm: An update. In R. F. Levant \& W. S. Pollack (Eds.) A new psychology of men (pp. 11-32). New York: Basic Books.

Saunders, J. B., Aasland, O. G., Babor, T. F., de la Fuente, J. R., \& Grant, M. (1993). Development of the Alcohol Use Disorders Identification Test (AUDIT): WHO collaborative project on early detection of persons with harmful alcohol consumption: II. Addiction, 88 (6), 791-804. https://doi.org/10.1111/j.1360-0443.1993.tb02093.x

St. Clair, J. (2020, 11/18). Masculinity was on the ballot this year, and Americans chose a different version of it. WKSU. Retrieved from: https://www.wksu.org/governmentpolitics/2020-11-18/masculinity-was-on-the-ballot-this-year-and-americans-chose-adifferent-version-of-it

Wampold, B. E. (2010). The research evidence for the common factors models: A historically situated perspective. In B. L. Duncan, S. D. Miller, B. E. Wampold, \& M. A. Hubble (Eds.), The heart and soul of change: Delivering what works in therapy(p. 49-81). American Psychological Association. https://doi.org/10.1037/12075-002

Wester, S. R., Vogel, D. L., O'Neil, J. M., \& Danforth, L. (2012). Development and evaluation of the Gender Role Conflict Scale Short Form (GRCS-SF). Psychology of Men \& Masculinity, 13 (2), 199-210. https://doi.org/10.1037/a0025550 